\title{
Implementing lean leadership in garment industries
}

\author{
L. B. Al-Badareen \\ University of Debrecen, Faculty of Engineering, Department of Mechanical Engineering, \\ laithbadareen@yahoo.com
}

\begin{abstract}
Garment industries are one of the most competitive industries nowadays, that was the main reason why implementing lean tools became conventional between big brands, although, lean tools alone are not enough for successful lean implementation in any organization, that's why creating lean leaders and defining what lean leadership exactly means became a necessity, in this study, we will try to draw a path in which garment manufacturers can pursue to become lean organizations taking a (Manufacturer for NIKE) as an example for the study as a heavy lean implementer closing by suggesting a 9 steps method that lean can be implemented successfully in garment industry factory.
\end{abstract}

\section{Introduction}

There are a variety of new production technologies coming onto the scene, but lean manufacturing is taking the spotlights, especially when it is connected to Toyota and how it survived the global financial crisis, however, lean principles appears to be simple, many lean implementation attempts fail shortly to fetch expected results. When analyzing these failed attempts, It was clear that those organizations shorten the lean with implementing the lean tools only, like (6S, SMED, Kanban...etc) but those organizations probably didn't give enough attention to the other aspects of lean (people and leadership) which might be invisible but highly essential for a successful lean implementation because lean is not a toolkit and cannot be dealt with as a toolkit. [6]Lean failure can be directly attached with many factors like exaggeration in complacency, failure in creating a team, lack of vision, or letting obstacles to block the vision, miscommunication between management and workers and other [4], most of these factors and others can be avoided with good leadership that have vision with eager to change, Taking that into consideration, lean leadership have achieved its high value and needed to be studies in details. considering that garment industry highly depends on human based processes and so far, technology could not make it fully automated [1], empowering people became substantial to be able to produce products that can compete in the global market, here, the significance of lean leadership became obvious where leadership is considered the missing link or the connection between improving process and empowering people, in other words, it's the way to have improved process with empowering people in parallel. [10].

In this paper, the focus will be on lean leadership and highlighting how essential it is to end up by suggesting a 9 steps method to implement lean in garment factory focusing on the rule of leadership throughout the way. 


\section{Toyota Production System (TPS)}

Toyota is the brandmark and the first thing that comes to our mind when lean is talked about as it is the creator and the role model for this methodology, Toyota has managed to keep continuous steady growth and zero company layout since 1950, quality statistic top of the field, repeated customer satisfaction, [4] that's how TPS got attention and everyone started to ask about the strategy Toyota used to accomplish all that, the answer was (Lean) [10] [12] [13]. What is curious though is that only few manufacturers have managed to initiate Toyota successfully, even though the company was open about its practices, but many organizations failed in their attempts for many reasons. [9] Lean if implemented correctly can be developed from a process to behavior, then it can transform into a culture and that need years of parallel work of improving the process and impowering people, that's the goal all the lean implementers try to achieve which is adapting the methodology to be a culture, although, it's not an easy neither a quick transformation as it needs many years of practice in which all aspects of the organization will work side by side to get to that. [10] [12] [13] [16]

To understand TPS, the paradox have to be unrevealed, it is important to see that the rigid specifications is actually the thing that makes the flexibility and creativity possible, all the aspects of production in Toyota is scripted, yet, operations are extremely flexible and adaptable, then those activities are challenged and pushed for higher levels of performance and that's just not possible without developing all aspects of lean in parallel to each other. [9] What Eiji Toyoda who was one of the founding members of Toyota did can be formulated as following: decisions were made close to the value creation point using mainly data and facts, problem solving, and process design were made by the line managers, by higher managers asking questions rather than just give answers and putting chief engineer as prototypical lean manager. [8] Toyota did not create or chose TPS consciously, the system grew naturally out of working for decades following the scripted standards and applying it in a flexible creative way using the scientific method. [10] The management/leadership skills and methods can get a higher prior in maintenance and in robotics field too. [14] [15] Although we can try to formulate some rules to underline Toyota Production System as follows: [2]

- All work shall be highly specified as to content, sequence, timing and outcome.

- Every costumer-supplier connection must be direct, and there must be an ambiguous Yes or No way to send requests and receive responds.

- The pathway for every product and service must be simple and direct.

- Any improvement must be made in accordance with the scientific method under the guidance of a teacher at the lowest possible level in the organization. When organizations are managed according to the four rules, individuals are repeatedly conducting experiments, testing in operation the hypotheses built into the design of individual work activities, customer-supplier connections, path way and improvement efforts. [2]

\section{Lean leadership}

Lean is about creating ever more pure value with ever declining amounts of resources through developing the capability of everyone to improve flow and eliminate waste as they apply science to 
their work [4], this journey cant be done without leaders who truly understand it and believe in it, from here the importance of discussing the characters of the leaders who can lead this transformation came from. [7] John Maxwell once said, "Everything rises and falls in leadership" [11] indeed, any improvement, any project or vision can't be applied without leaders who truly believe in it and work hard to achieve it and lean as every other project count on the leadership. [2] [13]

Lean leadership is about knowing your role in the organization and how to interpret it, in short, lean is a philosophy. It is not about turning people loose and expecting or hoping that their natural goodness or creativity will emerge to carry forward your dreams, it's also not the extreme opposite when we order people and tell them what to do, [7] a way should be found in between without intervening directly in the problem-solving process and try to promote problem solving process. Maybe someone will ask why it's not efficient to just tell the people what they have to do, well, by doing that it will take the responsibility out of them, deprive them from the opportunity to think never forgetting that you might actually be wrong which will put you as a leader in a bad position. [6] Now lean leadership as an important aspect of lean is a methodologic system for the sustainable implementation and continuous improvement of the system as whole, it describes the cooperation of employees and leaders in their mutual striving for perfection. [2]

The basic elements for lean leadership are improvement culture, self-development, qualification, Gemba and Hoshin Kanri, [2] lean leadership is not to be a dictator who dominate decision making process, it's also not about not interfering at all when people needs help, lean leadership is when the leader say, 'I don't know exactly where this will take us but let's find out together, we will try to have a common understanding to where we want to go and how we will make it there'. In other words, leader act like a coach aiming to develop capability through purposeful instruction, targeted questioning and challenging consul to solve problems and continuously improve performance in achieving objectives. [9] It's about ownership and having the courage to grab the bull from the horn, and go straight to the front-line workers, let them know that their suggestions and opinion matters, they should know that as a part of the organization they must be part of the continuous improvement in all aspects. [9] A key took to achieve that is the upside-down organizational chart. [6]

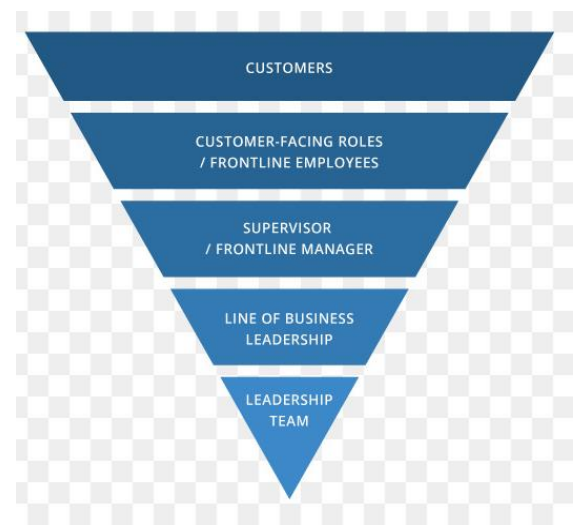

Figure 1: The upside-down organizational chart [11]

The figure above is important because it reminds front line workers along with all levels of management the reason why they do what they do which is creating value for customer, it remind us 
that it is the responsibility of all levels of management, stuff and support functions to support the processes that creates value for the customer, this is a central message in lean, and through lean, the management and the rest of organization are reminded that it is their job to support and develop the core process es that involve the work of too many employees that have a customer in the receiving end. The up side down organizational chart is more than just a graph or diagram, it shows the respect of the company towards customer-oriented work which is the main core in all organizations. [6]

Taking that into consideration, lean leaders have 3 attributes at every level in the organization that show their true value and they are as following: [8] Go and see, visit the point where value is being created and verify the situation.

- Ask why, what is the problem? What are the possible counter measures? Why one counter measure is the best?

- Show respect: Assign clear responsibility for every process and problem, ask questions about people's work. [8]

All levels of management should know what tasks are headed to them, the senior management sets direction with strategy and feedback lops, middle management solve horizontal and cross cutting problems with A3, front line management stabilizes processes and steadily improves them through standard work and management with kaizen. [8]

Lean leadership have five fundamental principles that describes the core base of lean leadership and they are the following: [2]

- Improvement culture: In lean management, mistakes are learning opportunity, provide that the core cause is identified, leaders must focus on encouraging employees to report mistakes by creating a no blame culture under which mistakes will not be punished. In addition, the core cause of mistake or a failure must be identified in the process rather in the person, a good example for that is Toyota production line where approximately 15000 problems are reported daily and dealt with in a minute time. [10] To enhance reporting the problem, leaders are recommended to introduce the Andon system, a cord that employees can pull to warn management on a failure, it's important to know that this method can only be efficient if the management responds every time that employee pull the cord. [7]

- Self-development: In lean leadership, self-development consists of that leaders have to explain clearly what lean production is and the reason why organization strive to implement it, then, leaders have to be responsible for arranging material and effective training sessions to introduce lean to employees, then they have to point out and clarify the purpose of lean and relate training plans for achieving it. [2]

- Qualification: All employees need to be developed individually, although, learning must take place in short cycles. The long-term development is a central quality for lean, it's also a precondition to include employees in CIP, autonomous problem solving is among the least accomplished goals and requires long term employee development. Quick leaning cycles though result in quick feedback and thus, quick success in learning, both promote employee motivation and contributes to their autonomous and continuous improvement, we should not forget to implement PDCA along the way. [6] [2]

- Go Gemba: An incremental approach to change the organizational level requires everyone specially leaders, to have a clear understanding of the direction of that change, Gemba is the place where the work is done which is considered as a challenge for leaders. [2] There are 3 types of Gemba walks, the first one is considered proactive which is daily management (KPI based leader 
standard work), second is reactive where leader deal with the problem in the minute the problem occurs, the last is going Gemba in regular basis not for a particular reason other than see what people are doing. [8] We should take into consideration that Gemba walks should not exceed 15 minutes, otherwise it will be considered as a waste. Gemba walks happen for some reasons like understanding current reality, learning about obstacles to stuff success and discover the need for additional improvements. It's also important to assure the alignment of department goals and improvements activities, communicate and reinforce organizational vision goals and priorities. The location of the manager's office should be located in a place which make it easy to reach the gemba to achieve the purpose. [8]

- Hoshine Kanri (Policy deployment): \{Before we build cars, we build people\} [1] this proverb of Toyota very well illustrates the high importance of employee development. Thus, employee development must be highly rated in the target system. The process can only be good as the employee. For this reason, both must be developed equally. [7] It can be defined as a principle which aligns the activities of people throughout the company so that the company can achieve key goals and react quickly to a changing environment. With Hoshine planning, the aim is to share goals down from top level, [2] while sharing results from down up to management. In this way Hoshine Kanri considered unique as it discus the opening of communications and discussion of goals rather than the actual implementation of the process itself. It starts with establishing organizational vision, then developing breakthrough objectives, develop annual objectives then deploy them, implement annual objectives, do monthly reviews then finally, do annual review. [2]

\section{9 steps to implement successful lean in garment industry}

Some recommended steps to implement successful lean in garment industry factory taking (Nike) manufacturer as an example without forgetting to highlight the role of senior management and leaders in the process [1].

Management decision: Garment industries are one of the most competitive markets now a days, taking that its mostly human based industry into consideration [1], implementing lean became a must to be able to compete as raising prices of output became not efficient anymore, for that reason, that why it could be fair to say that convincing the management and making the decision toward this change is easier than other industries, the tricky part is implementing it successful. Although, an openminded management who has the courage to take this decision is a must as a first step toward successful lean journey. [8]

Implementing lean could be driven by other factors such as implementing it as a solution for declining productivity and output, or, it could be a requirement when you have big clients like (NIKE).

Leaders training: The second step is to train potential lean leaders in lean methodology, it's important that this group understand lean and believe in it as a philosophy, also, they should have enough knowledge to deal with lean tools and have the capability for transferring this knowledge to other parts of organization in different ways depend on the targeted group.

Set mission, vision and policy: After potential leaders are trained, those leaders should meet with the senior management and discuss the current situation and how to start the implementation, from that, lean mission and vision are agreed on and then scripted and understood in a way that make it easy to deliver for other parts of the organization from middle management to front line workers. Lean 
committee from different departments will be established to cooperate with the leaders. It's important that the vision and mission should be based on meeting the customer requirements.

Introduce the new change to others: The next step would be involving everyone and introduce the new mission and vision with a basic lean training for all levels in the organization to understand the new change, know what is required for them and what is their role.

Analyze current situation: In this step. VSM (Value stream map), skills matrix, process map and process chart are some of the tools that can be used for this purpose. The aim of this step is to collect data which will help you later to decide where to start the process of waste elimination and to measure future improvements.

Standardization: In this step, lean leaders start to build the standards in the organization focusing on health, safety and improving processes that add value and meet customer requirements, creating SOPs implementing $6 \mathrm{~s}$ and spreading team work concept by conducting workshops for this purpose.

Prepare a training plan: There are two types of trainings, Behavioral training focusing on the soft skills including lean workshops and technical trainings which depends on the skill matrix, the aim of these trainings is to empower the people of the organization which is considered an essential aspect of lean, this will be reflected in the performance of the organization as a whole.

Involving people in CIP (Continues Improvement Process): After the previous steps are implemented, employees in all organization levels should be involved in the lean journey, this could be achieved by creating a system in which everyone can suggest kaizens and implement them. Kaizen is a really important aspect of lean, employees' level of thinking should develop to reach a stage where they can find kaizens. A solid example for that is the method used by our case study company, The Golden Idea where the best kaizen will get rewarded which will encourage all employees to participate [1].

Sustain: Lean can never be shortened with a process, it is not just a period of the company life, lean is revolutionary aspect where you have to keep following up with all processes happening using Hoshine Kanri and never forget that there is always space for further improvements.

\section{Conclusion}

Most lean conversions fails to deliver the promised benefits or hold the initial gains, this disappointment comes from the believe that lean in just about cost reduction, [9] which means it comes from focusing in the process and forgetting the other aspects, it requires a constant lean management and to sustain it, a change is needed in the mind set and behavior of the leaders, then gradually throughout the organization .Lean success occurs when senior leaders put appropriate structures and processes in place and get personally involved in sustaining the lean conversion. In this paper, TPS was explained as the role model of lean implementation worldwide, lean leadership concept was explained in details, then a suggested 9 steps method for implementing lean was listed, the case study was a garment manufacturer and lean leadership term were taken into consideration. 


\section{References}

[1] Pine Tree for Textile Manufacturing: NOS orientation ppt presentation, 2018 (inside presentation).

[2] U. Dombrowski, Lean leadership - 15 rules for sustainable lean implementation, In Science Direct, (Pdf).

[3] Lean Enterprise Institution: Lean Lexicon 5th Edition, In Lean Enterprise Institution (online) https://www.lean.org/lexicon/toyota-production-system .

Pine Tree for Textile Manufacturing: Lean Culture ppt presentation, 2018 (inside presentation).

[4] A. Chiarini (2011) From Total Quality Control to Lean Six Sigma (Pdf).

[5] C. Sehested (2011) Lean Innovation a fast path from knowledge to value. (Pdf).

[6] U. Dombrowski, Lean leadership - fundamental principles and their applications, In Science Direct, (Pdf).

[7] Pine Tree for Textile Manufacturing: Day 5 - 08. Lean Leadership Development (English Ver.), 2018 (inside Pdf).

[8] J. Shook (2017) John Shook in lean leadership-Singapore SIT CXC summit, In Lean Enterprise Institute YouTube channel (YouTube) https://www.youtube.com/watch?v=6w471E57Z3M.

[9] S. Spear: Decoding the DNA of the Toyota Production System, In Harvard Business Review (Pdf).

[10] Organizational chart organizational structure, In Kisspng https://www.kisspng.com/pngorganizational-chart-organizational-structure-hier-6134565/

[11] Amitabh Saxena: Top 3 reasons why some lean and six sigma projects succeed, while others don't, In Linkdin (online) https://www.linkedin.com/pulse/top-3-reasons-why-some-lean-six-sigma-projectssucceed-amitabh-saxena/ accessed at 28/10/2018

[12] J. Ményhárt (2018) Basics of Maintenance Engineering. Debrecen: Dupress, ISBN 978963318 7470

[13] E. Szűcs - J. Ményhárt (2018) Minőségbiztosítás, az elmélet és ami mögötte van. Debrecen, Magyarórszág : Debreceni Egyetem. ISBN: 9789634900375

[14] R. Szabolcsi - J. Ményhárt (2015) Loads Affecting UGV's Technical Status. REVIEW OF THE AIR FORCE ACADEMY /REVISTA AFA / REVISTA ACADEMIEI FORTELOR AERIENE 30/2015 : No3 pp. 15-20. , 6 p.

[15] R. Szabolcsi - J. Menyhárt (2015) The Importance of Maintenance During UGV Use, REVISTA ACADEMIEI FORTELOR TERESTRE / LAND FORCES ACADEMY REVIEW No4 : 80/2015 pp. 486492. , 7 p.

[16] A, Matkó ; T, Takács (2017) Examination of the relationship between organizational culture and performance, INTERNATIONAL REVIEW OF APPLIED SCIENCES AND ENGINEERING 8 : 1 pp. 99105. , 7 p. 